\title{
Shall We Treat All Patients with Hepatitis C, and if Not, Why? Certainly, Injecting Drug Users Must Not Be an Exclusion Criterion
}

\author{
Hans L. Tillmann ${ }^{\mathrm{a}, \mathrm{b}} \quad$ Alexander J.V. Thompson ${ }^{\mathrm{a}}$ \\ ${ }^{a}$ Duke Clinical Research Institute, Duke University, Durham, N.C., USA; ${ }^{b}$ Medical Department II, \\ University Leipzig, Leipzig, Germany
}

Lacking a virus is mostly but not always better than carrying a virus [1].

In the current issue of Digestion, Fried et al. [2] describe their experience in using pegylated interferon and ribavirin (PEG/RBV) for the treatment of a heterogeneous group of 67 hepatitis $\mathrm{C}$ virus (HCV)-infected patients within Swiss opiate substitution programs containing some 1,700 patients. HCV infection affects the majority of former and current injecting drug users (IDUs). Controversy persists about whether treatment is appropriate for patients who remain in drug dependency programs, or are current IDUs. Perceived obstacles largely relate to the increased incidence of psychosocial morbidity in this population, as well as concerns regarding treatment-related toxicity and non-compliance. Much of this controversy has centered on the following questions: (1) Will patients tolerate the treatment? (2) Will patients adhere to the treatment? (3) Is it therefore possible to achieve acceptable sustained virologic response (SVR) rates? (4) Not part of controversies, but important in that setting too, is the question whether earlier described prognostic factors such as $\gamma$-glutamyl transferase and cholesterol, week 4 and week $12 \mathrm{HCV}$-RNA can predict the outcome.

In their study, Fried et al. confirm the findings of several earlier publications as they cite that SVR rates are comparable to the results achieved in studies of non-IDU populations. In line with previous studies, they note a high rate of side effects and a discontinuation rate of almost a quarter. To our knowledge, this is the first published experience from the Swiss healthcare medical system. A common theme of successful treatment programs is the use of a multidisciplinary approach, as employed by Fried et al., often with directly-observed therapy, incorporating specialists in hepatology/infectious diseases, addiction medicine and psychiatry, as well as specialist nursing and allied health staff. Such resources are not widely available. It remains unclear whether analysis of the health economics would support greater availability. Although not specifically addressed in this article, antiviral therapy has also been shown not to have a major impact on the need for increasing doses of opiate replacement therapy, nor on injecting patterns [3-5].

Fried et al. present data analyzing treatment outcome according to virological response at week 12 . This is consistent with previous literature in non-IDU patients, showing that failure to achieve a week 12 rapid virological response (RVR) predicts for low likelihood of SVR (9.1\%) rate. The positive predictive value was relatively low (71 vs. $61 \%$ in the overall cohort). This low positive predictive value is due to the relatively insensitive viral load assay used in this study (lower limit of detection of $600 \mathrm{IU} / \mathrm{ml}$ rather than the currently acceptable limit of 50 or even $6 \mathrm{IU} / \mathrm{ml})$. The authors further miss the chance to give

\section{KARGER \\ Fax +4161306 1234 \\ E-Mail karger@karger.ch}

www.karger.com
(C) 2008 S. Karger AG, Basel

0012-2823/08/0783-0120\$24.50/0

Accessible online at:

www.karger.com/dig
H.L.Tillmann

Duke Clinical Research Institute, Duke University

2400 Pratt Street

Durham, NC 27705 (USA)

Tel. +1 919668 4620, Fax +1 919668 7164,E-Mail hans.tillmann@duke.edu 
new information such as predictive value of the week 4 HCV-RNA negativity, failure to achieve a 1-log drop by week $4, \gamma$-glutamyl transferase and cholesterol values in those patients.

Does the fact that we can successfully treat these patients mean that we should? Let us challenge the presumption that everyone should be treated, and consider questions that all clinicians should ask themselves before starting any patient on anti-HCV therapy. Does the patient benefit from this treatment, and is it wiser to treat now or would it be better in a few years? Which questions need to be addressed to valuably answer this question? Is there a reasonable risk that this patient will suffer from liver-related morbidity or mortality? Will his long-term health-related quality of life improve or worsen with treatment?

When HCV was discovered, most of us believed that almost all HCV-infected patients would eventually die from liver failure or hepatocellular carcinoma given the high prevalence of $\mathrm{HCV}$ in NANB-cirrhotic patients. It has, however, become clear that progression is slow [6] and the majority of patients infected with HCV will not die of liver disease. In our experience, this is a common source of patient confusion. As demonstrated by Fried et al., this patient population is typically young, and therefore at very low risk for significant liver disease. For patients with F0 or F1 fibrosis, there is no data to support a benefit of clearing the virus. In fact, mortality risk from continued drug use is of much greater concern in this population [7]. In most patients with advanced fibrosis, alcohol is likely to be a significant cofactor and sustained abstinence of more immediate importance.

HCV-RNA clearance is used as a surrogate. Trusting in surrogate markers can turn out to cost lives instead of saving lives $[8,9]$. It has not been proven that HCV clearance translates into clinical benefit for all $\mathrm{HCV}$ patients [10].

Liver biopsy is a useful tool for stratifying patients if advanced liver disease $(>F 2)$ is suspected. Of course, in patients with advanced liver disease who achieve a SVR, there is clear data that the outcome is improved compared to those without such viral clearance. But treatment of $\mathrm{HCV}$ is unlikely to provide a significant liver-related morbidity or mortality benefit for most patients, and it is important that patient education addresses this fact. We all too frequently forget to question the initial presumptions. Most believe that treating HCV leads to benefit, but this actually until today has not been shown [11].

Could treatment programs impact on the HCV epidemic in IDUs? As demonstrated by Fried et al., patients receiving therapy represent the tip of the iceberg - only $4 \%$ of HCV-positive IDUs in Swiss opiate substitution programs were treated for their infection. Thus, such intervention is unlikely to modify the epidemiology of HCV substantially.

Even in the absence of benefit in relation to liver disease, treatment could be indicated if quality of life and rehabilitation (social and professional), which is especially important in IDU patients, would be improved. Treatment with PEG/RBV clearly causes on-treatment decline in health-related quality of life (HRQOL) $[12,13]$. HRQOL post-treatment is closely associated with treatment outcome, increasing in those achieving a SVR. However, improvement after initial severe deterioration might lead to overestimation of indeed achieved improvement. Thus, long-term evaluation will be required.

HRQOL in this difficult-to-treat and psychosocially vulnerable population has not been properly assessed in the literature. Chronic hepatitis $\mathrm{C}$ alone appears to directly compromise HRQOL [14]. Objective assessment can therefore be complicated, but needs to be addressed in randomized trials [15]. Whether treatment leads to improved HRQOL, and perhaps a 'motivation for social change', or whether treatment in fact decreases HRQOL, through psychosocial and economic difficulties is not known. It is central to the issue of whether treatment should be advocated early, or whether treatment should be deferred.

Randomized controlled trials with one arm serving as a control are required to answer the following important questions: (1) Improvements in physical or psychosocial (including indices of HRQOL and social/professional rehabilitation) well-being? (2) Change in patterns of drug use? (3) What is the ideal model for these treatment programs, and how can they be justified through health economic analysis? (4) Can response-guided therapy improve compliance rates by allowing shortened duration of therapy or early (week 4 ?) stopping rules?

Primum non nocere (first do not harm). PEG/RBV therapy has well-recognized toxicity. In 50\% of patients, treatment will not be successful using the currently available standard of care $[16,17]$. We are on the verge of a new era in the treatment of chronic hepatitis C. Small molecule inhibitors of HCV have now entered phase 3 trials. They hold the promise of shortened treatment duration, less toxicity, and improved SVR rates, but for the foreseeable future all will require interferon. If $\mathrm{HCV}$ is not successfully cleared, interferon resistance might still be induced and weakens interferon's efficacy in future treatment options. There is good in vitro evidence for 
development of interferon resistance on cellular level [18]. Similarly, I have seen patients in referral after their fourth interferon course failed, who showed less response with every course of interferon. Thus, burning interferon now might decrease the chance to clear HCV when direct antivirals come into the clinic.

We are convinced that once HCV can be cured with higher efficacy, fewer side effects and short treatment duration, everyone will undergo therapy, until then however, we shall carefully judge what is best for the individual patient.

Finally, an ethical dilemma remains concerning an individual's right to be free of a certain infection vs. the society's right to pay as little as needed. As indicated, it seems that this study by Fried and his Swiss colleagues was co-sponsored by Roche (donation of RBV and support for the study conduct) and the Swiss healthcare insurance system (paying for PEGASYS and monitoring). Unfortunately, societal stigma is still attached to the diagnosis of chronic hepatitis C. In our view though, current or former IDUs must have the same rights to treatment for HCV as all members of society. Frank discussion of the difficulties encountered in treating this patient population though should not be considered discriminatory.

\section{References}

1 Tillmann HL, Heiken H, Knapik-Botor A, Heringlake S, Ockenga J, Wilber JC, Goergen $B$, Detmer J, McMorrow M, Stoll M, Schmidt RE, Manns MP: Infection with GB virus $\mathrm{C}$ and reduced mortality among HIVinfected patients. N Engl J Med 2001;345: 715-724.

2 Fried R, Monnat M, Seidenberg A, Oppliger R, Schmid P, Herold M, Isler M, Broers B, Kölliker C, Schönbucher P, Frei M, Huber M: Swiss multicenter study evaluating the efficacy, feasibility and safety of peginterferonalfa-2a and ribavirin in patients with chronic hepatitis $\mathrm{C}$ in official opiate substitution programs. Digestion 2008;78:123-130.

-3 Sylvestre DL: Treating hepatitis C in methadone maintenance patients: an interim analysis. Drug Alcohol Depend 2002;67:117123.

4 Van Thiel DH, Anantharaju A, Creech S: Response to treatment of hepatitis $\mathrm{C}$ in individuals with a recent history of intravenous drug abuse. Am J Gastroenterol 2003;98: 2281-2288.

5 Mauss S, Berger F, Goelz J, Jacob B, Schmutz G: A prospective controlled study of interferon-based therapy of chronic hepatitis $\mathrm{C}$ in patients on methadone maintenance. Hepatology 2004;40:120-124.
Tillmann HL: Hepatitis C virus infection. N Engl J Med 2001;345:1426.

-7 Amin J, Law MG, Bartlett M, Kaldor JM, Dore GJ: Causes of death after diagnosis of hepatitis B or hepatitis C infection: a large community-based linkage study. Lancet 2006;368:938-945.

$\checkmark 8$ Cardiac Arrhythmia Suppression Trial (CAST) Investigators: Preliminary report: effect of encainide and flecainide on mortality in a randomized trial of arrhythmia suppression after myocardial infarction. $\mathrm{N}$ Engl J Med 1989;321:406-412.

$\checkmark 9$ Eshaghian S, Horwich TB, Fonarow GC: An unexpected inverse relationship between HbA1c levels and mortality in patients with diabetes and advanced systolic heart failure. Am Heart J 2006;151:91.

10 Gluud C, Brok J, Gong Y, Koretz RL: Hepatology may have problems with putative surrogate outcome measures. J Hepatol 2007;46: 734-742.

11 Tillmann HL: Hepatitis C virus infection. N Engl J Med 2001;345:1426.

12 Ware JE Jr, Bayliss MS, Mannocchia M, Davis GL, The Interventional Therapy Group: Health-related quality of life in chronic hepatitis C: impact of disease and treatment response. Hepatology 1999;30:550-555.
3 McHutchison JG, Ware JE Jr, Bayliss MS, Pianko S, Albrecht JK, Cort S, Yang I, Neary MP, Hepatitis Interventional Therapy Group: The effects of interferon- $\alpha_{2 b}$ in combination with ribavirin on health-related quality of life and work productivity. J Hepatol 2001;34:140-147.

14 Foster GR, Goldin RD, Thomas HC: Chronic hepatitis $C$ virus infection causes a significant reduction in quality of life in the absence of cirrhosis. Hepatology 1998;27: 209-212.

15 Younossi Z, Kallman J, Kincaid J: The effects of HCV infection and management on health-related quality of life. Hepatology 2007;45:806-816.

16 Manns MP, McHutchison JG, Gordon SC, Rustgi VK, Shiffman M, Reindollar R, et al: Peginterferon alfa-2b plus ribavirin compared with interferon alfa- $2 \mathrm{~b}$ plus ribavirin for initial treatment of chronic hepatitis C: a randomised trial. Lancet 2001;358:958-965.

17 Fried MW, Shiffman ML, Reddy KR, Smith C, Marinos G, Goncales FL Jr, et al: Peginterferon alfa-2a plus ribavirin for chronic hepatitis C virus infection. N Engl J Med 2002; 347:975-982.

17 Aus dem Siepen M, Oniangue-Ndza C, Wiese M, Ross S, Roggendorf M, Viazov S: Interferon- $\alpha$ and ribavirin resistance of Huh7 cells transfected with HCV subgenomic replicon. Virus Res 2007;125:109-113. 